\title{
Intravenous patient-controlled analgesia to manage the postoperative pain in patients undergoing craniotomy
}

\author{
Hyo-Seok $\mathrm{Na}^{1}$, Sang-Bum An², Hee-Pyoung Park ${ }^{2}$, Young-Jin Lim² ${ }^{2}$ Jung-Won Hwang ${ }^{1}$, Young-Tae \\ Jeon $^{1}$, and Seong-Won Min ${ }^{3}$ \\ Department of Anesthesiology and Pain Medicine, ${ }^{1}$ Seoul National University Bundang Hospital, Seongnam, ${ }^{2}$ Seoul National \\ University Hospital, ${ }^{3}$ Seoul National University Boramae Medical Center, Seoul, Korea
}

Background: This randomized controlled study evaluated the efficacy of intravenous patient-controlled analgesia (IV-PCA) with fentanyl and ketorolac for neurosurgical patients, and compared the effectiveness of IV-PCA with intermittent analgesics injection.

Methods: The patients undergoing craniotomy were randomly assigned to two groups. Patients of group $\mathrm{P}(\mathrm{n}=53)$ received fentanyl $(0.2 \mu \mathrm{g} / \mathrm{kg} / \mathrm{hr})$ and ketorolac $(0.3 \mathrm{mg} / \mathrm{kg} / \mathrm{hr})$ via IV-PCA, and those of group N (n = 53) received intermittent fentanyl or ketorolac injection as needed. Pain was evaluated using a 0-10 visual analogue scale (VAS) at postoperative 1, 4, and $24 \mathrm{hr}$. The amount of infused analgesic drugs, Glasgow Coma Scale (GCS) score, systolic arterial pressure, heart rate, respiratory rate, and the incidence of nausea and miosis were measured at the same time points.

Results: Although VAS of pain (VASp) was comparable at postoperative $1 \mathrm{hr}(\mathrm{P}=0.168)$ between the two groups, the group $\mathrm{P}$ had significantly lower VASp at postoperative $4 \mathrm{hr}(\mathrm{P}=0.007)$ and $24 \mathrm{hr}(\mathrm{P}=0.017)$. In group $\mathrm{P}$, less analgesic drugs were administered at postoperative $1 \mathrm{hr}$, and more analgesic drugs were administered at postoperative $24 \mathrm{hr}$. There were no differences between two groups with respect to nausea, GCS, systolic arterial pressure, and heart rate. IV-PCA did not further incur respiratory depression or miosis.

Conclusions: IV-PCA with fentanyl and ketorolac after craniotomy is more effective analgesic technique, without adverse events, than the intermittent administration of analgesics. (Korean J Anesthesiol 2011; 60: 30-35)

Key Words: Craniotomy, Fentanyl, Ketorolac, Patient-controlled analgesia.

Received: June 25, 2010. Revised: 1st, July 23, 2010; 2nd, August 24, 2010. Accepted: August 24, 2010.

Corresponding author: Seong-Won Min, M.D., Department of Anesthesiology and Pain Medicine, Seoul National University Boramae Medical Center, Boramae-gil, Dongjak-gu, Seoul 156-707, Korea. Tel: 82-2-870-2512, Fax: 82-2-870-3863, E-mail: swmin@brm.co.kr

Presented in part at the annual meeting of the Korea Society of Neuroanesthesia, Seoul, Korea, 2008.

(c) This is an open-access article distributed under the terms of the Creative Commons Attribution Non-Commercial License (http:// creativecommons.org/licenses/by-nc/3.0/), which permits unrestricted non-commercial use, distribution, and reproduction in any medium, provided the original work is properly cited. 


\section{Introduction}

It was generally thought that patients undergoing craniotomy experience minimal pain during the postoperative period. However, the recent reports have indicated that post-craniotomy pain is a real headache and more severe than anticipated [1]. It was sometimes managed insufficiently and treated with only on-demand analgesic medication. Intramuscular codeine phosphate was reported to be the first-line drug for relieving post-craniotomy pain in the majority of the neurosurgical centers of the UK in 2005 [2].

Insufficient pain control after craniotomy can increase the intracranial pressure in patients with compromised cerebral autoregulation, and arterial or intracranial hypertension can lead to intracranial hemorrhage. Moreover, most neurosurgeons want to ascertain the neurological results as early as possible, so cautious postoperative pain management is required so as not to disturb the neurological assessment after craniotomy.

The superiority of potent opioids such as morphine, codeine and oxycodone rather than weak analgesics has been proved in neurosurgical patients [3-6], and scalp nerve block has also been tried [7] for achieving better pain relief in craniotomy patients. Intravenous patient-controlled analgesia (IV-PCA) using both opioids and NSAIDs is a common method for the treatment of acute postoperative pain after general surgery [8-12] because it is possible to maximize the analgesic effect through the different mechanisms of the drugs while at the same time not increasing the side effects. Although some neuroanesthesiologists have pointed out that the postcraniotomy patients are too uncooperative to benefit from PCA [13], early recovery has been a current trend after intracranial procedures, so we think that IV-PCA can be used by these patients.

We evaluated the efficacy and safety of IV-PCA composed of fentanyl and ketorolac in postcraniotomy patients by conducting this randomized controlled study.

\section{Materials and Methods}

After getting approval from the Institutional Review Board, informed written consent was obtained from all the patients scheduled for elective intracranial surgery. This randomized controlled trial was conducted on patients with a physical status of I or II according to the American Society of Anesthesiologist classification. The eligible criteria were preoperative Glasgow Coma Scale (GCS) score of 15 and female or male adults aged 20-70. The preoperative exclusion criteria were as follows: morbid obesity, prolonged postoperative ventilatory care, difficulty in using IV-PCA, and chronic medication with analgesics and other drugs that could influence the postoperative pain (steroid, antiepileptic drugs and gabapentin).

Patients were randomly assigned to two groups using the sealed envelope method; the IV-PCA group (group P) or the intermittent analgesic drugs injection group (group $\mathrm{N}$ ). We explained the 0-10 visual analogue scale (VAS) ruler assessing the postoperative pain to all the patients, and gave detailed instruction for the IV-PCA to the patients of group P. The IVPCA (AutoMed ${ }^{\circledR} 3200$, ACE Medical Corp., Ltd, Seoul, Korea) of group P was composed of fentanyl and ketorolac. Fentanyl $20 \mu \mathrm{g} / \mathrm{kg}$ and ketorolac $3 \mathrm{mg} / \mathrm{kg}$ (rounded off to the nearest multiple of $50 \mu \mathrm{g}$ and $10 \mathrm{mg}$, respectively) were made up to 100 $\mathrm{ml}$ in normal saline and the infusion rate, bolus dose, and lock time interval were set at $1 \mathrm{ml} / \mathrm{hr}, 1 \mathrm{ml}$, and $15 \mathrm{~min}$, respectively [14].

Standard monitoring (ECG, non-invasive arterial pressure, and pulse oximetry) was established in the operating room. Anesthesia was induced and maintained using propofol and remifentanil by target controlled infusions (TCI) using an Orchestra ${ }^{\circledR}$ infusion pump system (Fresenius vial, Brezins, France). After loss of consciousness, neuromuscular block was achieved with rocuronium $0.6 \mathrm{mg} / \mathrm{kg}$, followed by tracheal intubation. Patients were ventilated with $50 \%$ oxygen in air with maintaining the end-tidal $\mathrm{CO}_{2}$ level between $30-35 \mathrm{mmHg}$. Both invasive arterial pressure and central venous pressure were monitored in each patient as routine practice. Propofol and remifentanil were discontinued after skin closure and IVPCA was started for the patients of group P. After the operation, patients were transferred to the intensive care unit (ICU) and extubation was performed after recovery from the anesthesia.

During the postoperative period, the patients of group $\mathrm{P}$ used the IV-PCA according to the prior instruction. In group N, when patients complained of pain, VAS score of pain (VASp) was checked and if necessary, a rescue analgesic drug such as ketorolac or fentanyl was administered. If VASp was 7 or more, then $1 \mu \mathrm{g} / \mathrm{kg}$ of fentanyl was administered, and if VASp was $4-6,0.5 \mu \mathrm{g} / \mathrm{kg}$ of fentanyl was used. When VASp was 2 or 3 , $30 \mathrm{mg}$ of ketorolac was injected, and no additional analgesics were administered for VASp of 0 or 1 . This was determined with considering the basal and bolus doses of IV-PCA in group $P$ based on the VASp of $1-3=$ mild pain, $4-6=$ moderate pain, and $7-10=$ severe pain [15].

VASp and the cumulative amount of infused analgesic drugs were assessed at postoperative 1, 4, and $24 \mathrm{hr}$, and the GCS score, pupil size and hemodynamic variables (systolic arterial pressure, heart rate, and respiratory rate) were evaluated at the same time points. In addition, the incidence of nausea was evaluated in both groups.

Data were expressed as mean \pm SD. The patients' characteristics were analyzed using Student's t-test. VASp, the amount of infused analgesic drugs, GCS scores, and hemodynamic 
variables were analyzed by repeated measures ANOVA, and when there was a significant difference between the two groups, Mann-Whitney U-test was performed at individual time points. The incidences of nausea and pupillary miosis, which is a constricted pupil less than or equal to $2 \mathrm{~mm}$ under ambient light, were compared with the chi-square test. In a preliminary study, we estimated that 53 patients were required in each group to show a difference of 11 (20) in VASp to give a statistical power of $80 \%$ and a type I error of $5 \%$. Statistical analyses were performed using SPSS version 15.0 (SPSS Inc., Chicago, IL, USA). P values of $<0.05$ were considered statistically significant.

\section{Results}

One hundred twelve patients consented to participate in this study. Five patients were excluded during the postoperative period because ventilatory support care under sedation

Table 1. Patients' Characteristics and Type of Operation

\begin{tabular}{lcc}
\hline & $\begin{array}{c}\text { Group P } \\
(\mathrm{n}=53)\end{array}$ & $\begin{array}{c}\text { Group N } \\
(\mathrm{n}=53)\end{array}$ \\
\hline Age (yr) & $49.9 \pm 15.9$ & $44.0 \pm 13.8$ \\
Height (cm) & $169.7 \pm 8.6$ & $171.4 \pm 42.1$ \\
Weight (kg) & $62.6 \pm 10.1$ & $65.2 \pm 10.2$ \\
Gender (M/F) & $22 / 31$ & $25 / 28$ \\
Supratentorial/Infratentorial & $42 / 11$ & $37 / 16$ \\
Operation time (hr) & $6.7 \pm 1.2$ & $7.0 \pm 1.4$ \\
Anesthesia time (hr) & $7.3 \pm 0.9$ & $7.9 \pm 1.1$ \\
\hline
\end{tabular}

Values are expressed as mean \pm SD or number of patients (n). Group P: postoperative use of intravenous PCA for pain control. Group $\mathrm{N}$ : intermittent analgesic drug administration for postoperative pain control. There were no significant differences between the two groups.

Table 2. Postoperative Visual Analogue Scale of Pain and Cumulative Amount of Fentanyl and Ketorolac in Two Groups

\begin{tabular}{lccc}
\hline & $\begin{array}{c}\text { Group P } \\
(\mathrm{n}=53)\end{array}$ & $\begin{array}{c}\text { Group N } \\
(\mathrm{n}=53)\end{array}$ & P value \\
\hline VASp-1 & $4.2 \pm 2.5$ & $5.1 \pm 2.2$ & 0.168 \\
VASp-4 & $3.3 \pm 2.1$ & $4.8 \pm 2.6$ & $0.007^{*}$ \\
VASp-24 & $2.3 \pm 1.6$ & $3.4 \pm 2.3$ & $0.017^{*}$ \\
Fentanyl-1 & $0.27 \pm 0.05$ & $0.59 \pm 0.44$ & $0.001^{*}$ \\
Fentanyl-4 & $1.35 \pm 0.24$ & $1.38 \pm 0.86$ & 0.590 \\
Fentanyl-24 & $7.42 \pm 0.77$ & $1.75 \pm 0.99$ & $<0.001^{*}$ \\
Ketorolac-1 & $0.04 \pm 0.01$ & $0.14 \pm 0.23$ & $<0.001^{*}$ \\
Ketorolac-4 & $0.20 \pm 0.04$ & $0.39 \pm 0.40$ & 0.085 \\
Ketorolac-24 & $1.10 \pm 0.11$ & $0.87 \pm 0.55$ & $0.002^{*}$ \\
\hline
\end{tabular}

Values are expressed as mean \pm SD. Group P: postoperative use of IV-PCA for pain control. Group N: intermittent analgesic drug administration for postoperative pain control. VASp: visual analogue scale of the pain. Fentanyl $(\mu \mathrm{g} / \mathrm{kg})$ : cumulative dose of fentanyl. Ketorolac (mg/kg): cumulative dose of ketorolac. 1, 4 and 24: at postoperative 1,4 and $24 \mathrm{~h}$ respectively. *Values are significantly different between the two groups. was intentionally applied for a while, and two patients were withdrawn from group $\mathrm{P}$ because vomiting required that the IV-PCA be stopped. None of the patients had postoperative hemorrhage that required surgical removal. Patients' characteristics and surgical data (site of operation and duration of anesthesia and operation) are shown in Table 1.

Although VASp was comparable between the two groups at postoperative $1 \mathrm{hr}(\mathrm{P}=0.168)$, group $\mathrm{P}$ had significantly lower VASp at postoperative $4 \mathrm{hr}(\mathrm{P}=0.007)$ and $24 \mathrm{hr}(\mathrm{P}=0.017)$ (Table 2). In group $\mathrm{N}$, fentanyl (whatever the dose and number of injection are) was administered to 46 patients (86.8\%) and ketorolac was given to 7 patients $(13.2 \%)$ at postoperative $1 \mathrm{hr}$. Until postoperative $4 \mathrm{hr}$, fentanyl and ketorolac were injected to 34 patients $(64.1 \%)$ and 14 patients $(26.4 \%)$, respectively. When evaluating at postoperative $24 \mathrm{hr}$, fentanyl and ketorolac were administered to 16 patients $(30.2 \%)$ and 26 patients (49.1\%), respectively. Only one patient received no analgesics throughout the postoperative $24 \mathrm{hr}$. The cumulative doses per body weight of fentanyl and ketorolac are presented on Table 2. Patients of group $P$ received significantly less fentanyl and ketorolac than group $\mathrm{N}$ at postoperative $1 \mathrm{hr}(\mathrm{P}=0.001$ for fentanyl and $\mathrm{P}<0.001$ for ketorolac), however, the total dose of fentanyl and ketorolac of group $\mathrm{P}$ was much more than that of group $\mathrm{N}$ at postoperative $24 \mathrm{hr}(\mathrm{P}<0.001$ for fentanyl and $\mathrm{P}=$ 0.002 for ketorolac). There was no difference between the two groups for the cumulative dose of each drug at postoperative 4 $\mathrm{hr}(\mathrm{P}=\mathbf{0 . 0 5 9}$ for fentanyl and $\mathrm{P}=\mathbf{0 . 0 8 5}$ for ketorolac $)$.

GCS score was over 13 and it showed no significant differences between both groups (Table 3). Hemodynamic variables also had no significant differences (Table 3), and pupillary miosis

Table 3. Glasgow Coma Scale and Arterial Systolic Pressure, Heart Rate and Respiratory Rate of the Two Groups

\begin{tabular}{lcc}
\hline & Group P $(\mathrm{n}=53)$ & Group N $(\mathrm{n}=53)$ \\
\hline GCS-1 & $13.4 \pm 1.6$ & $13.8 \pm 0.7$ \\
GCS-4 & $14.2 \pm 1.0$ & $14.5 \pm 0.6$ \\
GCS-24 & $14.7 \pm 0.5$ & $14.9 \pm 0.4$ \\
SBP-1 & $138.3 \pm 15.3$ & $138.9 \pm 15.0$ \\
SBP-4 & $130.9 \pm 19.7$ & $127.4 \pm 20.1$ \\
SBP-24 & $128.0 \pm 17.4$ & $125.6 \pm 13.5$ \\
HR-1 & $87.6 \pm 18.7$ & $83.9 \pm 15.3$ \\
HR-4 & $89.7 \pm 20.9$ & $82.0 \pm 16.5$ \\
HR-24 & $80.0 \pm 19.6$ & $77.6 \pm 15.8$ \\
RR-1 & $18.9 \pm 4.2$ & $19.2 \pm 2.9$ \\
RR-4 & $18.7 \pm 5.1$ & $18.4 \pm 2.3$ \\
RR-24 & $17.7 \pm 3.9$ & $18.3 \pm 2.1$ \\
\hline
\end{tabular}

Values are expressed as mean \pm SD. Group P: postoperative use of IV-PCA for pain control. Group N: intermittent analgesic drug administration for postoperative pain control. GCS: Glasgow Coma Scale, SBP (mmHg): systolic blood pressure, HR (beats/min): heart rate, $\mathrm{RR}$ (breaths/min): respiratory rate. 1,4 and 24 : at postoperative 1, 4 and $24 \mathrm{hr}$ respectively. There were no significant differences between the two groups. 
masking the signs of intracranial problems was not observed in both groups. There was no difference in the incidence of postoperative nausea between the two groups (35.8\% vs. $32.1 \%$ for group $\mathrm{P}$ vs. group $\mathrm{N}, \mathrm{P}=0.501$ ).

\section{Discussion}

In this prospective, randomized controlled study, we proved that IV-PCA with fentanyl and ketorolac could provide superior analgesia in craniotomy patients without any major adverse events or any disturbances on the neurological examination.

IV-PCA is widely used to manage postoperative pain. It generally leads to greater patient satisfaction and better analgesic efficacy allowing the patients to exert self-control over their pain $[16,17]$. Nevertheless, in a survey of Stoneham and Walters [13], some neuroanesthesiologists indicated that the neurosurgical patients were too uncooperative to benefit from PCA. In addition, post-craniotomy pain has generally been treated inadequately $[18,19]$ with a previous concept that post-craniotomy pain was not so severe and on-demand analgesic medication was enough [20,21]. Recently, however, postoperative pain control using the PCA does not thought to be the matter in neurosurgical department with a tendency towards waking up the patients in early postoperative period. Our patients also nearly regained consciousness at immediate postoperative time regardless of the group.

To best of our knowledge, no previous study has investigated the use of IV-PCA combined with opioids and NSAIDs following craniotomy, although other types of PCA with morphine, oxycodone or fentanyl alone have been reported as suitable methods for pain control for this patient population [3,4,22]. We added the ketorolac to the intravenous fentanyl based PCA so we could achieve more distinct pain control in group $P$.

NSAIDs have a potential, although small, for causing postoperative bleeding by disturbing platelet function. This has caused the neuroanesthesiologists and neurosurgeons to have a passive attitude for using NSAIDs. However, none of our patients required an operation because of postoperative intracranial hematoma, although the number of our subjects was too small to draw firm conclusion about the safety of NSAIDs after craniotomy. Through this study, we can recommend that the proper use of NSAIDs may enhance analgesia without increasing the NSAID-related side effects, and the optimal supplementary dose of NSAIDs should be determined by future studies.

As fentanyl is a roughly 50 to 100 times more potent lipophilic opioid than hydrophilic morphine [23], we choose it because of its more rapid onset than morphine and shorter duration when it is administered intravenously. We expected that these properties would reduce the postoperative pain during the early postoperative period. Also, with being used in continuous smaller doses, we thought fentanyl might cause analgesia during the recovery period without the accumulation or prolonged duration. Corresponding with this assumption, postoperative pain scores of group $\mathrm{P}$ were consistently lower than those of patients in group $\mathrm{N}$.

The infused volume via IV-PCA was very low ( $1 \mathrm{ml}$ or a little more) at postoperative $1 \mathrm{hr}$, so the analgesic dose of group $\mathrm{N}$ could be more than that of group P. However, the difference of the amount of infused drug did not cause the difference of VASp at postoperative $1 \mathrm{hr}$. Interestingly, the smaller amount of infused drug of group $\mathrm{P}$ at postoperative $1 \mathrm{hr}$ was reversed after postoperative $24 \mathrm{hr}$. The patients of group $\mathrm{P}$ received the analgesic drugs continuously throughout the period by the IVPCA, which contained the basal flow rate $(1 \mathrm{ml} / \mathrm{hr})$ with a bolus dose $(1 \mathrm{ml})$. It would only be natural that the VASp became lower when more analgesic drug was administered via IV-PCA in group P. However, this study is valuable as it showed that IVPCA efficiently relieves postcraniotomy pain without interfering with the neurologic evaluation or lowering the GCS score, and this attests the ineffectiveness of intermittent analgesic injection, that is, insufficient analgesics and inadequate pain control shown in our group $\mathrm{N}$.

Regardless of these affirmative results, what will be challenging for using opioids clinically after craniotomy is probably the adverse events such as sedation, respiratory depression, nausea and vomiting. These opioid related side effects were rare in this present study, except for nausea. It was thought that the addition of ketorolac to intravenous fentanyl PCA might provide an opioid sparing and so reduce these events.

We assessed the GCS scores of patients to evaluate the postoperative consciousness. Traditionally, coma using the GCS score is classified as severe with GCS $\leq 8$, moderate with GCS $9-12$, and minor with GCS $\geq 13$ [24]. Although a slightly lower GCS was assessed at postoperative $1 \mathrm{hr}$, it became over 14 from postoperative $4 \mathrm{hr}$ in both groups. It means that the state of consciousness of group $\mathrm{P}$ was not different from that of group $\mathrm{N}$. The patients had almost a minor coma status postoperatively, and actually there was no difficulty or erroneous masking when performing the neurologic examinations after the operation. Considering the report that fentanyl preserved cognitive function better than morphine [25], fentanyl is thought to be more appropriate to manage the moderate to severe pain of neurosurgical patients.

Our results also confirmed that the respiratory rate of both groups were not different. Prolonged ventilator care was not done except for the five cases of performing intentional sedation postoperatively. If we had measured the $\mathrm{PaCO}_{2}$ at each time point, it would have been sure to confirm specifically and objectively that fentanyl of IV-PCA had little effect on respiratory 
function. In addition, there was no difference in the incidence of nausea between the two groups. Although the IV-PCA was stopped in two patients of group $\mathrm{P}$ during the postoperative period due to vomiting, the overall incidence of nausea was similar in the two groups and antiemetic drugs improved that symptom. It has already been reported that intravenous opioid PCA-related nausea and vomiting were effectively reduced by antiemetic drugs [26]. Further study is needed concerning if IVPCA with pretreatment of antiemetic drugs can reduce the PCArelated nausea and vomiting, and so it will be more effective in neurosurgical patients.

We recognize several limitations of this study. First, when interpreting the GCS scores, it is notable that the individual elements as well as the sum of the GCS are important clinically. Anything among the eye, verbal and motor responses can influence the GCS score, however we just compared the total score and cannot distinguish which one was a major factor for lowering the score. Next, we did not create subgroups according to the surgical approach (supratentorial or infratentorial) or gender. There was a tendency of more intensive pain in females and infratentorial surgery as compared to the males and supratentorial surgery [19]. In contrast to the previous study, there were no significant differences with respect to gender or surgical approach in the present study. We assume that this could reach statistical significance with a large number of patients. Last, the number of enrolled patients was small to detect the incidence of adverse events. This study was designed to address the differences in pain control, not complications. Further larger patient population are needed to assess the safety issue.

In conclusion, our results suggest that IV-PCA with fentanyl and ketorolac provides better postoperative analgesia after craniotomy and this can be a safe and effective analgesic technique for neurosurgical patients.

\section{References}

1. Talke PO, Gelb AW. Postcraniotomy pain remains a real headache! Eur J Anaesthesiol 2005; 22: 325-7.

2. Roberts GC. Post-craniotomy analgesia: current practices in British neurosurgical centres--a survey of post-craniotomy analgesic practices. Eur J Anaesthesiol 2005; 22: 328-32.

3. Stoneham MD, Cooper R, Quiney NF, Walters FJ. Pain following craniotomy: a preliminary study comparing PCA morphine with intramuscular codeine phosphate. Anaesthesia 1996; 51: 1176-8.

4. Tanskanen P, Kyttä J, Randell T. Patient-controlled analgesia with oxycodone in the treatment of postcraniotomy pain. Acta Anaesthesiol Scand 1999; 43: 42-5.

5. Jeffrey HM, Charlton P, Mellor DJ, Moss E, Vucevic M. Analgesia after intracranial surgery: a double-blind, prospective comparison of codeine and tramadol. Br J Anaesth 1999; 83: 245-9.
6. Sudheer PS, Logan SW, Terblanche C, Ateleanu B, Hall JE. Comparison of the analgesic efficacy and respiratory effects of morphine, tramadol and codeine after craniotomy. Anaesthesia 2007; 62: 555-60.

7. Ayoub C, Girard F, Boudreault D, Chouinard P, Ruel M, Moumdjian R. A comparison between scalp nerve block and morphine for transitional analgesia after remifentanil-based anesthesia in neurosurgery. Anesth Analg 2006; 103: 1237-40.

8. Cepeda MS, Carr DB, Miranda N, Diaz A, Silva C, Morales O. Comparison of morphine, ketorolac, and their combination for postoperative pain: results from a large, randomized, double-blind trial. Anesthesiology 2005; 103: 1225-32.

9. Chen JY, Wu GJ, Mok MS, Chou YH, Sun WZ, Chen PL, et al. Effect of adding ketorolac to intravenous morphine patient-controlled analgesia on bowel function in colorectal surgery patients--a prospective, randomized, double-blind study. Acta Anaesthesiol Scand 2005; 49: 546-51.

10. Munro HM, Walton SR, Malviya S, Merkel S, Voepel-Lewis T, Loder RT, et al. Low-dose ketorolac improves analgesia and reduces morphine requirements following posterior spinal fusion in adolescents. Can J Anaesth 2002; 49: 461-6.

11. Mercadante S, Fulfaro F, Casuccio A. A randomised controlled study on the use of anti-inflammatory drugs in patients with cancer pain on morphine therapy: effects on dose-escalation and a pharmacoeconomic analysis. Eur J Cancer 2002; 38: 1358-63.

12. Reuben SS, Connelly NR, Steinberg R. Ketorolac as an adjunct to patient-controlled morphine in postoperative spine surgery patients. Reg Anesth 1997; 22: 343-6.

13. Stoneham MD, Walters FJ. Post-operative analgesia for craniotomy patients: current attitudes among neuroanaesthetists. Eur J Anaesthesiol 1995; 12: 571-5.

14. Momeni M, Crucitti M, De Kock M. Patient-controlled analgesia in the management of postoperative pain. Drugs 2006; 66: 2321-37.

15. Breivik H, Borchgrevink PC, Allen SM, Rosseland LA, Romundstad L, Hals EK, et al. Assessment of pain. Br J Anaesth 2008; 101: 17-24.

16. Walder B, Schafer M, Henzi I, Tramèr MR. Efficacy and safety of patient-controlled opioid analgesia for acute postoperative pain. A quantitative systematic review. Acta Anaesthesiol Scand 2001; 45: 795-804.

17. Macintyre PE. Safety and efficacy of patient-controlled analgesia. $\mathrm{Br}$ J Anaesth 2001; 87: 36-46.

18. De Benedittis G, Lorenzetti A, Migliore M, Spagnoli D, Tiberio F, Villani RM. Postoperative pain in neurosurgery: a pilot study in brain surgery. Neurosurgery 1996; 38: 466-9.

19. Gottschalk A, Berkow LC, Stevens RD, Mirski M, Thompson RE, White ED, et al. Prospective evaluation of pain and analgesic use following major elective intracranial surgery. J Neurosurg 2007; 106: 210-6.

20. Dunbar PJ, Visco E, Lam AM. Craniotomy procedures are associated with less analgesic requirements than other surgical procedures. Anesth Analg 1999; 88: 335-40.

21. Klimek M, Ubben JF, Ammann J, Borner U, Klein J, Verbrugge SJ. Pain in neurosurgically treated patients: a prospective observational study. J Neurosurg 2006; 104: 350-9.

22. Morad AH, Winters BD, Yaster M, Stevens RD, White ED, Thompson $\mathrm{RE}$, et al. Efficacy of intravenous patient-controlled analgesia after 
supratentorial intracranial surgery: a prospective randomized controlled trial. J Neurosurg 2009; 111: 343-50.

23. Bovill JG, Sebel PS, Stanley TH. Opioid analgesics in anesthesia: with special reference to their use in cardiovascular anesthesia. Anesthesiology 1984; 61: 731-55.

24. Sternbach GL. The Glasgow coma scale. J Emerg Med 2000; 19: 6771.

25. Herrick IA, Ganapathy S, Komar W, Kirkby J, Moote CA, Dobkowski
W, et al. Postoperative cognitive impairment in the elderly. Choice of patient-controlled analgesia opioid. Anaesthesia 1996; 51: 35660.

26. Choi YS, Shim JK, Yoon DH, Jeon DH, Lee JY, Kwak YL. Effect of ramosetron on patient-controlled analgesia related nausea and vomiting after spine surgery in highly susceptible patients: comparison with ondansetron. Spine (Phila Pa 1976) 2008; 33: E602-6. 